\title{
La Evolución Textual de Huasipungo de Jorge Icaza
}

$J^{\circ}$ ORGE Icaza revisó su novela más célebre dos veces; sin embargo, esta preocupación del autor no ha recibido la debida atención, ni en los datos que se refieren a las varias ediciones se alude al hecho de tratarse de versiones revisadas. ${ }^{1}$ Las revisiones revelan un cambio gradual en el concepto que tiene Icaza sobre el indio del Ecuador y sirven para ilustrar su creciente preocupación por la forma literaria. Huasipungo-traducido a doce idiomas, incluyendo el chino y el ruso- ha gozado de gran fama como un documento que retrata en los términos más toscos la situación abyecta del indio. Considerado como literatura, su distinción principal era la fuerza y la intensidad dinámica de la narración. En el presente estudio de una selección representativa de los cambios hechos por Icaza en sus dos revisiones de la novela le veremos tratar un mismo tema en tres etapas de su desarrollo artístico. Finalmente, habrá que considerar la pertinencia de la opinión crítica establecida, una vez determinados la inciole y el alcance de las alteraciones.

La reputación literaria de Icaza se basa principalmente en esta primera novela, publicada cuando el autor no tenía más que veintiocho años. Sería muy natural entonces que quisiera revisar la obra, para pulir el estilo y corregir los errores debidos a descuido o a falta de experiencia. Sin embargo, para explicar por qué había hecho la revisión Icaza dijo:

1 La Editorial Losada, S. A., de Buenos Aires publicó la primera revisión en septiembre de 1953 y la segunda en mayo de 1960 . La versión final se en. cuentra también en las Obras escogidas (México: Aguilar, 1961). Tampoco aquí hay mención de que se trata de una revisión. Parece que hasta el difunto crítico ecuatoriano, Francisco Ferrandiz Alborz, quien afirma haber hecho "la relectura de la obra total de Jorge Icaza para un prólogo de esta edición de Aguilar", ignoró dichas revisiones. Pues, en su prólogo (admirable por lo demás) cita varias veces de la versión intermediaria de la novela - citas que no existen en el Huasipungo, sumamente distinto, que prologa. 
Hice la revisión de la novela llevado de un deseo de darle mayor claridad para el mundo internacional. Al escribir la novela no creí que ella pudiera tomar un vuelo hacia todas las latitudes ¿el mundo. Mi afán era regional - que sirviera de mensaje y emoción a las gentes de mi pueblo para la resolución de sus problemas. Pero la dificultad de las traducciones en los giros y en las palabras se hacía cada vez más infranqueable. En tal virtud me vi, casi obligado, a la revisión. ${ }^{2}$

Bien puede ser que su preocupación por las dificultades de la traducción le haya movido a emprender la revisión, pero este fin limitado fue reem. plazado pronto por un deseo de hacer de Huasipungo una novela de técnica superior: "Considero que cuanto hice en la revisión recae solamente en los elementos de la técnica novelística". ${ }^{3}$

Su método de revisar, al principio, era escudriñar infatigablemente el texto, cambiar una palabra aquí, tachar una frase allí. El examen riguroso reveló trozos confusos, p.ej., "la choza india ... con ... techumbre de paja renegrida por la lluvia y el humo que, sin hallar salida, se filtra por todas partes" (I, I8) 4 A veces, como aquí, la solución consistió simplemente en añadir una palabra: ". . sin hallar salida: normal, se filtra..." (II, I6).$^{5}$ Clarificó las posibles ambigüedades, p.ej., "all llegar a un cruce, don Alfonso..." ( $\left.I, 1_{2}\right)$ reexpresado como "al llegar a un cruce ćel camino, don Alfonso..." (II, I2). Eliminó la repetición monótona: "lodo... calle lodosa" ( $(I, I 7)$ alterado a "lodo... calle fangosa" (II, I5); "el Andrés... camina con el trote de las caminatas urgentes" (I, 22) a "el Andrés... se adelanta con el trote de las caminatas urgentes" (II, I8). Dividió en dos —o recortó- las frases pesadas para dar mayor claridad y concisión: así la exclamación ansiosa de Alfonso Pereira, el latifundista, "Estos criminales irán despertando lentamente, de tiempo en tiempo, con tintes cada vez más espeluznantes, hasta que..." (I, I46) se rećujo a "Estos criminales se levantarán algún día..." (II, II4). Reemplazó los vulgarismos con las palabras correctas: un ingrediente de una bebida medicinal, "caca de cuy molida" ( $I, 98)$ más

2 De una carta personal de Icaza, fechada el 2 de febrero de 1964.

3 Ibid.

4 El I romano indica la edición original (Quito: Imprenta Nacional, 1934); el II romano, la primera edición revisada (Buenos Aires: Losada, 1953); el III romano, la segunda edición nuevamente revisada y amplificada (Buenos Aires: Losada, 1960).

5 La letra itálica es siempre mia. 
respetable, aunque no más genuina, como "excremento molido de cuy" (II, 80).

Notamos también correcciones gramaticales como "los viejos... luciendo cintillos tricolores en los sombreros de paja" (I, 79) rectificando a "los viejos... luciendo cintillo tricolor en el sombrero de paja" (II, $6_{5}$ ). Icaza eliminó la materia superflua y, especialmente, las frases que rebajaban la integriciad artística de la obra como, p.ej., el cliché del malvado traidor de melodrama, "-iCastigo del cielo!- dice don Alfonso frotándose las manos lleno de satisfacción" (I, I26). El lector moderno no podría reprimir una sonrisa ante tal frase; así pues, para mantener el tono sumamente serio, ésta se redujo a "-iCastigo del cielo! —concluyó don Alfonso" (II, IOO).

Además de muchas alteraciones menudas y frecuentes cambios de puntuación hay en la primera revisión un énfasis mayor en la presentación dramática - muy natural, pues Icaza siempre ha tenido estrechas relaciones con el teatro. Crea más diálogo vívido y sabe derivar el efecto máximo de las situaciones dramáticas; en vez de describir lo ocurtido, nos permite presenciarlo.

Siempre se ha considerado a Huasipungo como la novela de las masas par éxcellence, en la que los indios no se diferencian mucho de los animales. Aparentemente Icaza quiere alterar este concepto. Suprimió frases como "Ios indios... se agrupaban unos a otros desvirtuando su personalidad y creando una personalidad de masa" (I, I39). Los indios, antes lánguidamente resignados a su existencia bestial, ahora sienten y expresan - aunque furtivamente - un resentimiento extremado contra sus opresores. El fermento que algún día tiene que conducir a la violencia se acentuó:

- ¿Entendiste, pendejo? -insistió el cholo.

-Arí, patrón - respondió el Andrés con la misma impasibilidad exterior del primer momento, mientras sus manos bajo el poncho se crispaban y maldecían (II, 3I).

Prolongó y dio mayor relieve al lamento ce Andrés por su mujer Cunshi -único ejemplo de emoción tierna de la versión original. Los miembros anónimos del coro indio recibieron nombre y personalidad, p.ej., las "dos mujeres" ( $\mathrm{I}, 37$ ) escogidas para nodrizas son ahora "Juana Quishpe" y "Rosario Caguango" (II, 30).

El proceso de individualización no se aplicó, sin embargo, a los ca- 
racteres principales. Al licencioso cura se le quitó el apellido-antes "el señor cura Lomas", ahora "el cura" o "el Santo Varón"- para acentuar que representa un tipo. Los intereses característicos de esta clase de hombre se especificaron: "- ¿Cómo está la política? ¿Ya cayó el Gobierno? ¿Cómo están las chiquillas buenas mozas?" (II, 5I); "También sabía of recer a manos llenas - llenas de lujuria y de secretas carias-bienes espirituales -fortuna para ultratumba- mientras hacía el amor el Santo Varón" (II, 58). Icaza subrayó la debilidad moral ce don Alfonso al añadir elementos tales como su manera de sobornar a la chola Juana: "-Cuando me separe de mi mujer, que será pronto, me casaré contigo. Te regalaré la vaca manchada. Te llevaré a Quito. Serás la patrona" (II, 58 ). Su cobardía estaba en contradicción con la osadía que exhibió entrando en la alcoba de Cunshi para ejercer su supuesto derecho señoril. Así, Icaza tuvo que enmendar "Empujó violentamente la puerta" (I, 57) a "Empujó la puerta con suavidad felina" (II, 46). Pero a pesar de los rasgos añadidos, don Alfonso queda como un personaje incompleto, sin relieve.

En su primera revisión Icaza se contuvo un poco para no perjucicar su arte. Preservó la esencia de declaraciones como "¡Es muy divertido verles [a los niños] hacer una masa de mierda, orines y tierra, para darle forma cubista en el molde de la mano!" (I, 34), pero sin el sarcasmo demasiado obvio. También parece que Icaza reconoció que el valor de Huasipungo era rebajado por la vituperación desenfrenada: " . . los barrotes que desde chicos les pusieron el cura, el amo, el teniente político, todos los blancos predicadores de moral, toćas las élites de la civilización que viven buscando espaldas sumisas sobre las cuales pase el carro del progreso, donde van ellos y sus satélites" ( $I$, I90). La eliminación de tal propaganda no perjudicó el mensaje implícito en el mismo relato.

Pero no todos los cambios de la primera revisión pueden considerarse como mejoras. Algunos hasta parecen ser innecesarios, p.ej., la riña de gallos (I, I07-I08) entre el «pintadito» del maestro de escuela y el pollo de José Santiana se presenta en la revisión (II, 87) entre el «negrito» del maestro ce escuela y uno de los pollos de don Alfonso. (José Santiana ya no figura en la novela). La exclusión de ciertos toques felices empobreció la obra, p.ej., el bello pasaje "El Andrés, la Cunshi y el guagua han pasado la noche bajo una peña, pero se hallan cercados por un enorme charco que se ha formado a la salida de la cueva; el guagua gateando, llega a ella, y hace pedazos, con la mano, aquel espejo donde el cielo se está mirando para pintarse con su primer carmín" (I, 90-9I), se suprimió, presumiblemente porque estorbaba en una situación de sufri- 
miento grave. Pero ¿no es que servía más bien para intensificar que para diluir el patetismo? Asimismo, es lamentable la desaparición del conmovedor "Se sienten encantados los guaguas oyendo algo que ellos se imaginan voladores o cohetes" ( $I, 209)$, de la escena final donde atacan a los huasipungueros con ametralladora.

Vemos, pues, que las alteraciones hechas por Icaza en su primera revisión son generalmente de importancia menor - la eliminación de obvios errores e inconsistencias, de monotonía y prolijidad; nueva puntuación y mejoramientos de gramática y fraseología- alteraciones que desearía hacer cualquier autor en una obra imperfecta de su juventud. Con excepción de su intento de individualizar a los indios, a la vez que de dibujar como tipos más nítidos a los personajes principales, la primera tevisión no es más que un pulimento del texto original, sin alterar mucho lo esencial de la obra. ${ }^{6}$

La segundáa revisión de Husisipungo, por otra parte, representa una transformación extensa. Icaza ha alterado la estructura original por medio de: a) introduciendo nuevas divisiones de capítulos; b) restaurando otros y c) por el proceso de añadir, omitir o revisar incidentes. Además, ha amplificado la novela en un veinte por ciento.

Lo primero que se nota al comparar las tres versiones es una divergencia en los tiempos verbales. Originalmente la relación se narraba casi por completo en el presente. La primera revisión colocó la acción en el pasado, conforme con la práctica novelística usual. Así se evitó la inconveniencia del tiempo presente para narrar un relato que dura un año, pero a costa de alejar al lector de la acción, en la cual la intensidad ce lo inmediato era uno de los méritos cardinales. La inclusión, en la versión final, de más y mejor diálogo, que retiene el interés del lector, mitiga en parte esta pérdida:

El terrateniente, despre. El terrateniente, desprecian. Sin pérdida de tiempo el ciando los comentarios, or- do todo comentario, orde- latifundista ordenó de nuedena al mayordomo: nó de inmediato al mayor- vo al mayordomo:

-Andá a traer otras dos domo: indias para que le den de - Tienes que traer otras longas.

mamar al guagua. Pero ve- dos indias para que den de - Si patrón. rás, carajo, que sean bue. mamar a mi hijo. ¡Verás - Las mejores. nas. carajo que sean buenas! -Así haremos.

-Así haremos, patrón -Así hatemos, patrón- El cholo Policarpio bus-murmura el Policarpio, respondió el cholo endere- có y halló a las mujeres

6 Aunque no se publicó hasta 1953, la p̣rimẹra rẹvisión fuẹ efectuada en sep. tiêmbre de 1951: 
enderazando la mula hacia zando su mula hacia el que necesitaba en una seel valle. valle.

En una sementera, a lo En una sementera enconmentera de papas. Al nolejos, unas pacas indias tró Policarpio lo que bus. deshierban un cebadal. Al caba. A lo lejos, unas notar la presencia del ma- cuantas indias desherbaban yordomo hunden más hon- los largos surcos de un pado las azadas. (I, 32-33). pal. Al notar la presencia del mayordomo hundieton tar la presencia del hombre -para ellas, cruel, altanero e intrigante- hundieron con fingido afán sus rústicas herramientas entre las más profundo las azadas. matas de los surcos... (III, 34-35). (II, 26).

Hemos notado arriba la más abundante dramatización de incidentes sobre los cuales anteriormente había pasado casi por alto. El mayor éxito de la versión final se debe, en parte, al uso dramático del tiempo presente, v.gr.:

Nadie se mueve; ronca el Abismado en temores y Nadie responde ni se muecapataz sobre un poyo, ron- sospechas esperaba, espera- ve a su primer atrevimien. can los indios sobre el ba con ansia prendida en to. Gatea con precaución suelo. El Andrés, aprove- la sangre: el sueño junto felina, palpando sin ruido chando las tinieblas que a la cunshi, la dulzura la paja pulverizada del sueborran contornos y el lodo de la caricia al guagua. lo. Se detiene, escucha, que suaviza el ruido de los pasos, se aleja; nadie sabe por dónde. $(I, 43)$.

Algo vital y valeroso, respita hondo. No calcula arrastrándole sin ruidos ni el tiempo ni el riesgo entre las respiraciones pro- que tendrá que utilizar por fundas del capataz que dor- el chaquiñán que corta al mía sobre un poyo-lo cerro-dos horas, dos hoúnico alto del recinto-, ras y media a todo anentre los ronquidos de ru- dar-, sólo piensa en la nas y arrieros tendidos por posibilidad de quedarse un el suelo, le liberaba del rato junto a la Cunshi y al cansancio, del temor, aven. guagua, de oler el jergón turándole fuera del gal. de su choza, de palpar al pón, y a través de la noche perro, de...: "Despacito... y los chaquiñanes. (II, Despacito, runa bruto", se 34-35).

dice mentalmente al pasar bajo el poyo donde duerme el capataz - único lugar un poco alto del recinto-. $Y$ pasa, y gana la salida, y se arrastra sinuoso por el lo. do, y se pierde y aparece entre las cien bocas húmedas dẹl chaparral, y gana 
la cumbre, y desciende la ladera, y cae rendido de cansancio y de bien ganada felicidad entre la longa y el hijo. (III, 45).

Algunos de los cambios reflejan la propensión de Icaza a dar un toque adicional a una escena ya bastante repugnante. Comparemos, por ejemplo, la frase "una acequia de agua turbia... donde los niños sacian la sed, es sórdida y maloliente" (I, I7; II, I5), con la alterada "la acequia de agua turbia... donde los niños se ponen en cuatro para beber, donde se orinan los borrachos". (III, 20). Hay también el episodio donde matan a un indio arrastrándose con un lazo desde una ciénega en la que se sumergía. Después de la segunda revisión, dos lazos ciñen a la víctima - uno por el cuello- para desmembrarle más efectivamente cuando le arrastran en dos direcciones.

El desarrollo artístico de Icaza es evidente en el estilo sutil y labrado de la última versión. Un trozo típico resulta primitivo al lado de su nueva expresión:

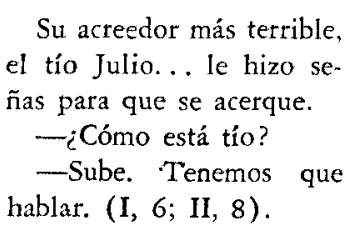

\author{
-Ven. Sube. \\ Era la fatalidad, era el \\ acreedor más fuerte, era el \\ tio Julio. Tenia que obe- \\ decer, tenía que acercarse, \\ tenía que sonreír. \\ - ¿Cómo. . .? ¿Cómo es- \\ tá, tío? (III, 8).
}

Siempre ha sido la anáfora recurso predilecto de Icaza, pero rara vez la usa $\tan$ eficazmente. Encontramos inesperadamente que Icaza -en otro tiempo brusco e inelegante - ahora emplea hasta la técnica modernista de sinestesia: así "anochecía en la soledad... bajo una garúa impertinente" ( $I, 42)$, se alteró a "anochecía temprano en el silencio gris... y el olor de la garúa... saturaba el ambiente" (III, 44). También notamos toques sutiles como el cambiar "[los indios] crian sus animales: cerdos, cuyes, gallinas" (II, I0), a "crían a sus animales" (III, I2), donde la mera adición de " $a$ " expresa el cariño de los indios para con sus animales. Huasipungo, conocido por su estilo crudo y poderoso, el ha logrado ahora una nueva dimensión.

En la yerșión final se describen detenidamente las caraçterísticas físịcas 
personales y se revelan los procesos mentales. Ahora se permiten que los indios piensen; antes se les retrataba tan incapaces de pensar como lo son de organizar su resistencia. "Sólo los indios... iban sin pensar en nada" (I, I6; II, I5), se reemplaza con una relación detallada de su preocupación con las necesidades materiales - la escasez de comida, la condición de la tierra, su anhelo de volver a la choza, el bienestar de sus hijos, esposas, padres, pollos, cercios, de las órdenes imposibles de Pereira, etc. (III, I9). Aquí tanemos uno de los medios que Icaza emplea para establecer su nueva opinión de que los indios también son gente. Describe el amor de Anćrés por Cunshi con mayor simpatía e intimidad en las revisiones sucesivas: p.ej.,

. .la choza donde tiene a . . la choza donde tiene el ...la choza donde le espela Cunshi. $(\mathrm{I}, 23)$. pecaminosa amor de la ra el amor de su Cunshi,... Cunshi. (II, 19). la longa que le tenía em. brujado, que olía a su gus. to, que cuando se acercaba a ella la sangre le ardía en las venas con dulce coraje, que cuando le hablaba todo era distinto en su torno - menos cruel el trabajo, menos dura la naturaleza, menos injusta la vida. (III, 25).

Suprime los episodios que representaban conducta bestial, disconforme con su concepción revisada del indio. Es decir, no quedan ya noticias como las siguientes: "Cesaron los ronquidos del indio tendido de bruces sobre el suelo pero no cesó la furia de los compañeros que pateaban, apaleaban, y hasta mordían a la presa" (II, 99); "El batallón de rapaces se entretuvo en ortigar a los cadáveres, en burlarse de ellos hurgándoles en la boca, en la nariz, en el trasero, en orinarles en las orejas" (II, I53).

Icaza dota con apellido a varios indios para darles mayor individualidad: Melchor es ahora Melchor Santos; Timoteo, Timoteo Mediavilla; José, José Tarqui. Melchor Montaquisa y Manuel Chimbayacu son nuevos personajes que sirven de priestes para una fiesta religiosa. De la aumentada atención prestada a los caracteres menores resultan muchas alteraciones nominativas que parecen carecer de propósito: a Melchor Morales le pone el nombre Melchor Alulema; a José Taxi, José Tixi; a José Rafael, José Risco; y un indio lleva un nombre distinto en cada versión-primero José Achig, luego Melchhor Achi, finalmẹnte Melchọr Cabascango. 
La actitud del autor para con el ingeniero de caminos fluctúa de tolerante a denunciatoria, y luego a ćesdeñosa. En el texto original el ingeniero vacilaba en sacrificar la vida de muchos indios para ganar tiempo. El gran malvado allí era don Alfonso. La segunda versión hizo destacar la amistad y complicidad estrechas entre los dos. Pero en la versión final el carácter del ingeniero es otra vez vacilante: se resiste y abandonaría el proyecto, sólo que don Alfonso le amenaza con denunciarle al ministro. También es distinta la concepción que ahora tiene Icaza de la hija de Alfonso Pereira. Lolita era antes un carácter insignificante, cuya única muestra de ánimo era que "urdía venganzas contra el perjuro Cumba" (I, I5-I6; II, I4). (Cumba es el cholo imperdonado que la dejó preñada). En la última versión (III, I9) sus emociones son otras: recuerda fascinada la sensación de las manos del cholo, sus besos, su olor, sus mentiras y ella misma acepta ser la responsable de su situación.

Por fin rectificó Icaza varias afirmaciones que chocaban con el carácter fundamental de los personajes. Por ejemplo, cuando el tío Julio explicaba que el proyecto requeriría la expulsión de los indios de sus huasipungos, Alfonso balbucia: "-Pero será necesario..." (I, 9; II, Io). De esto el lector entiende, por error, que Alfonso sentía algo de compunción. Icaza lo clarificó en la versión final al completar la pregunta: "-Pero usted cree que será necesario que yo mismo vaya y haga las cosas" (III, I I). Tampoco parecia verosímil lo fácil que le era a don Alfonso recordar el nombre de un indio en el momento de llegar a Tomachi: "--iCómo te va, Calupiña?" (I, I8; II, I6). El encuentro se redactó nuevamente así:

-Buenas tardes, patrones.

-Buenas tardes. ¿Quién eres? ¿Cómo te llamas? -interrogó en respuesta don Alfonso.

El Calupiña, pes.

-Ah! Sí. ¿Y cómo te va?... (III, 2I).

La cbservación, "los inciios trabajarán con mayores bríos hasta echar los bofes" (I, 63; II, 53), demasiaćo tosca para ser típica del cura, se reatribuye ahora al teniente político Jacinto Quintana. Otra confusión se presentaba cuando se decía de Jacinto que "se sentía orgulloso de haber edificado su casita de teja a fuerza de ahorrar honradamente en la tenencia política" (I, 25-26; II, 2I). ¿Seria posible que el teniente político no fuera siempre tan corrompido? Hubo de explicar más çlara- 
mente: ". . ahorzar honradamente las multas, los impuestos y las contribuciones fiscales que caían en la tenencia política" (III, 28).

Tal vez dudando de su validez psicológica, Icaza suprimió un pasaje respecto al sadismo. Anćrés encuentra a su guagua sola en la choza. Entra Cunshi. Viene de buscar leña. Ancirés monta en cólera y le da una paliza. ¿Por qué? "Estaba convencido que la afirmación de la hsmbra era verdad, pero su sexualidad desviada al sadismo por el látigo de los blancos se le escurrió por los dedos" ( $(1,24)$. La idea persistía con muy poca alteración en la segunda versión: "... sexualidad desviacia por el sadismo que le imprimió el látigo..." (II, 20). Al fin se abandona esta creencia de que el tratamento sádico convierte en sadista a la víctima. En la versión final la paliza se atribuye al temor de Andrés de que don Alfonso, quien acababa de llegar, descubriera su matrimonio prohibido.

Después de pegarle a su esposa, Andrés le hace el amor. De la descripción final del episodio se ha hecho cesaparecer la frase "El llanto de la Cunshi se apagó lentamente al sentirse hembra abierta por el hechizo del sexo" (I, 25; II, 20). La delicadeza parece haber inspirado también otros cambios. Por ejemplo, Alfonso Pereira citaba un artículo de fondo (I, II3) que comparaba su acción patriótica y las sociedaćes colonizadoras con el comercio del opio en China. En la segunda versión el editor lo defendía contra tal calumnia. Pereira sólo comprendía eso al acordarse de que su tío Julio era miembro cie un grupo que dominaba la prensa en el Ecuador (II, 90). Esta alegación de control de la prensa no figura en la versión final, pues el segundo artículo de fondo queda sin comentario (III, I I9). Debemos anotar, a propósito, que Icaza no ha borracio ninguna de las obscenidades ubicuas que, si bien pueden ofender, contribuyen al tono de verisimilidad en la novela.

Todo lector del Huasipungo original se ha preguntado por qué los indios se quedan voluntariamente en la minga, donde sufren tanta crueldad. Al revisar la novela Icaza formuló una respuesta inadecuada: "se quedaron por el aguardiente, por las exhortaciones del cura, y, sobre todo, por los gallos" (II, 89). Al hacer la segunda revisión introdujo otro factor: "algo mayor a la gana cie huir,... algo que llegaba de lejos ... impulso sembrado en el ancestro por taita Inca, orgullo de machismo patriótico..." (III, 96). Aquí vemos un parecer respecto al indio que se nota sólo en la obra reciente de Icaza. Ya no considera al indio como un animal, aunque en semejante estado tiene que vivir. 
Por el contrario, es el indio un ser abyecto y humillado que, sin embargo, respeta y ama sus tradiciones y leyendas, su herencia incaica.

El intento principal de Icaza al revisar Huasipungo era: "Dar!e claridad. Ese es el único criterio que me guió". ${ }^{8}$ El concepto que tenía Andrés del infierno, por ejemplo, necesitaba de clarificación: "el infierno era para él una poblada enorme de indios. No había blancos, no había curas, no había mayordomos ni tenientes políticos, la visión le tranquilizó" (I, 23; II, I9). Esta poćría ser más bien su visión del cielo. Hubo que añadir otra frase: "A pesar del fuego de las alimañas monstruosas, de los tormentos que observó de muchacho en uno de los cuadros del templo, la ausencia de los personajes anotados le tranquilizó mucho" (III, 26). Icaza eliminó lo prolijo: p.ej., de la difusión de "los chaparros enmarañados que se extienden al otro lado de la orilla del río" (I, 25; II, 20-2r) labró el más directo y conciso "del chaparral del otro laćo del río" (III, 28). La fraseología esmerada y la palabra exacta: "portazo" (III, 7) por "puertazo" (I, 5; II, 7); "nos hará millonarios a todos" (III, 9), en lugar del más relativo "nos hará ricos a todos" $(\mathrm{I}, 7 ; \mathrm{II}, 8)$.

Huasipungo es ahora, como ya dijimos, un veinte por ciento más amplio que la versión original. Pero no se debe tal expansión-como puede suponerse - sólo al hecho de haber incluido nuevos incidentes. En efecto, los hay; pero también había otros que ahora se omiten. La novela revisada es menos apresurada; su narración, más completa. El ambiente y los personajes se describen más detenidamente. Algunos detalles se han desarrollaco con provecho. Por ejemplo, antes se había contado sencillamente que a la longa que servía de nodriza al nieto de Pereira se le secó la leche cuando supo la muerte de su propio guagua y que fue preciso reemplazarla (I, 32; II, 26). Ni una palabra para describir la angustia de la madre. En la última versión Icaza cambió el enfoque:

La india, al oír aquello de su hijo, no pudo pronunciar una sola palabra - todo en su cuerpo se había vuelto rígido, estrangulado, inútil $\longrightarrow$, bajó la cabeza y se arrimó a la pared de la cocina donde se hallaba. Luego, como una autómata hizo las cosas el-resto de la tarde, y a la noche desapareció de la casa, del valle, del pueblo. Nadie supo después lo que hizo ni a dónde fue (III, 34).

Aun con tantos cambios, no ha habido ningún atentado de alterar

7 Cf. Huairapamusbcas (Quito: Casa de Cultura Ecuatoriana, 1948).

8 De la carta arriba citada. 
o amplificar el tema. "Es más bien una especie de trama subrayada sin tocar la esencia social y regional que ha tenido siempre Huasipungo".9 El último período de Icaza se caracteriza por su preocupación por las relaciones incómodas de los mestizos o cholos entre los blancos, que no los quieren aceptar, ${ }^{10}$ y los indios, a quienes dominan. La versión final de Huasipungo refleja esta preocupación. La frase "cualquiera que tenga la cara blanca y sepa leer en los papeles" (I, 44; II, 36), que denominaba el opresor, viene a ser "cualquiera que tenga la cara lavada y sepa leer en los papeles" (III, 47), dando a entencer que el indio está explotado así tanto por el cholo como por el blanco. Un recurso del que Icaza se vale para alinear a los cholos con los blancos es el de mejorar su habla: p.ej., "güenas", "aura" y "onde" ahora suenan "buenas", "ahora" y "donde" en boca de un cholo, pero no en la de un indio. Vanamente se esfuerza el cholerio en negar sus crígenes:

- Metido en el agua todito el día.

-Eso no, carajo.

-Eso sólo para los runas que ya están acostumbrados.

- Uno que al fin y al cabo es medio blanquito (III, $\mathrm{I}_{3}$ ).

Aspectos había de la novela que necesitaban de la modernización. Originalmente los Pereira salieron de Quito en tres mulas, seguidos ce portadores indios a pie (I, I2; II, I2). En la última versión, salen en tren para una estación remota en las montañas, donde les esperan indios y caballos (III, I4). Hasta t'o Julio demuestra el efecto de la vida moderna: su oficina, antes "aquella capilla de la austeridad" (I, 7; II, 8) se transformó en "aquel recinto de marcacio lujo de línea moderna" (III, 9). La deuda que tenía Alfonso "al Banco" (I, 6; II, 7) la tiene ahora "a los bancos" (III, 7). Aparece otra escala de precios ocasionaca por la inflación: don Alfonso, quien antes pagaba dos o tres sucres por cada indio (I, ro3; II, 85), ahora les compra con cinco o diez sucres; el cura en vez de cobrar a los indios veinte y cinco, quince y cinco sucres por el entierro en el campo santo $\left(I, 177 ; I_{1}, 136\right)$-el precio es según la proximidad al altar mayor - ahora demanda treinta y cinco, veinte y cinco, y cinco sucres (III, I67). [20 sucres $=$ I dólar $]$. Menos mal que Andrés recibe cincuenta sucres (en vez de cuarenta) por robar y vender una vaca para pagar el entierro cristiano cie su esposa. El gobierno manda 1958).

9 Ibid.

10 Cf. El chulla Romero y Flores (Quito: Casa de la Cultura Ecuatoriana, 
doscientos soldacios (antes trescientos) para exterminar a los huasipungueros. También la fidelidad histórica inspiró una alteración numérica: ¿Cuántos indios fueron muertos en el famoso levantamiento de Cuenca? "Mataron a todos. Más de mil runas quedaron tendidos" (I, 209; II, I55-156). Esto queda modificado a "Hubo que matar muchos. Más de cien runas" (III, I89).

Para el público internacional, al que se dirige ahora la novela, Icaza clarificó las referencias locales, p.ej., "don Gabriel García Moreno (I, I4; II,I3) alterado a "el Presidente García Moreno" (III, I7); reemplazó los giros poco usuales, p.ej., "meneó la cabeza como si estuviese al cabo de la calle" (I, 8; II, 9) con "meneó la cabeza afirmativamente como si estuviera enteracio del asunto" (III, Io). Asimismo para el lector extranjero hay más información sobre las responsabilidades del latifundista para con sus peones (III, I35-136).

Menos afortunados son otros aspectos de la revisión final. Las descripciones detenidas de caracteres y fondo, que aproximan Huasipungo a la forma novelística convencional, tienden a restringir el paso rápido, la progresión cinemática de sucesos, tan fundamental en esta novela. Hay unos errores mecánicos (p.ej., el cambiar el nombre de Juancho Cabascango a Tancredo Gualacoto en la página rig y no en la página 82), pero más grave es un defecto como la moralización excesiva que Icaza se permite aquí: "Para los demás - cholos, caballeros y patrones-, los dolores de los incíos son dolores de mofa, de desprecio y de asco. ¿Qué podía significar su angustia por la enfermedad de la india ante las complejas y delicadas tragedias de los blancos? ¡Nada!' (III, I 57). Es lamentable la supresión de ciertas frases y episodios pujantes. Durante la escena sangrienta, al final, "una ráfaga de ametralladora, con carcajada precisa, hundió para siempre en el agua turbia ... a las mujeres y a los niños" (II, I57). Alli "carcajada" era una figura muy apta, pero en la versión final dice sencillamente, "... cayeron también bajo el golpe inclemente de una ráfaga de ametralladora" (III, I9I). Cuanco Pereira rehusó dar "socorros" a los indios famélicos, algunas de las muchachas-notablemente Dolores y Rosa - fueron a la ciudad a prostituirse. Este episodio, omitido ahora, ilustraba eficazmente la desesperación de Melchor, quien reprobaba a sus hijas, pero quien tenía que aceptar la comida que le traían.

La selección que acabamos de presentar de las tres etapas del desarrollo textual de Huasipungo cemuestra que, a pesar de las tachas citadas, la obra es ahora más perfecta en cuanto a la técnica. Se han preservado 
el tono satírico y el auténtico drama humano. Hay mejoramientos en la forma, en el estilo, en la descripción. A los caracteres se les presenta ya con un poco ce complejidad psicológica. El lector que conoce sólo la versión revisada no comprenderá los juicios cŕticos usuales, v.gr.:

Ce qui caractérise d'abord Icaza, c'est sa violence: sens dramatique fougueux,... peinture de l'Indien comme être sous-humain ... C'est aussi l'objectivité: Icaza ne prêche jamais; ... on ne sent aucun effort pour faire «oeuvre d'art»; ... l'art n'est finalement que dans le mouvement; ... il n'a pas de psychologie personelle, il n'est pas assez riche pour pouvoir s'en payer une...11

Obviamente, ya no se puede discutir a Huatsipungo sin especificar qué versión.

La tesis esencial de Huasipungo ha sido la de que, por no establecer medidas correctivas, el gobierno ha permitido la reducción del indio a una especie subhumana. No puede dudarse de que al elevar al indio, Icaza debilitó mucho su acusación. Sin embargo, él considera que la última versión es superior a su obra original y quiete que la tomemos como el texto definitivo. ${ }^{12}$ Pero no siempre se atiende al deseo de un autor en esta cuestión. Por ejemplo, la edición crítica de Candide se basa en la original de 1759 y no en la versión amplificada de $176 \mathrm{r}$, porque fue la primera la que tuvo resonancia en el mundo literario. ${ }^{13}$ Huasipungo gozaba también de un sucicès de scandale en 1934, pero la súplica humana y el mensaje de que la rebelión no organizada tiene que fracasar, todavía hoy son válidos.

Al revisar la novela Icaza obró con arte y pericia para clarificar sus percepciones y recomendarlas lo más vitalmente que pudo a su público. Logró mayor universalidad, y sin sacrificar el colorido local. El nuevo Huasipungo - fruto literario más maduro-aguarda la consideración crítica, no como un mero folleto de acusación social, sino como una obra seria de literatura.

University of Toronto

ROSS F. LARSON

11 Robert Bazin, Histoire de la littérature américaine de langue espagnole (Paris: Libraire Hachette, 1953), p. 328.

12 En 1960 Icaza autorizó a Bernard M. Dulsey, de la University of Missouri en Kansas City, que tradujera al inglés la última versión amplificada. Esta traducción lleva el título, The Villagers (Carbondale, Ill.: Southern Illinois Universi. ty Press, 1964). En la carta antes citada Icaza la llama "una brillante traducción", y habla de otras traducciones hechas del texto final: "Sobre la última versión Losada ha hecho ya dos ediciones y se han hecho varias traducciones, al italiano, al checo y al inglés, donde el libro no había entrado todavía". En realidad, una edición inglesa furtiva fue publicada en Rusia por la Editorial Literatura Internacional de Moscú en 1936 pero, evidentemente, no tuvo gran tiraje.

133 Voltaire, Candide, ed. André Morize (Paris: Librairie E. Droz, 1913, reimpreso 1931). 